\title{
MÉTODO PARA DETERMINAR A RELAÇÃO DO PORTFÓLIO DE SERVIÇOS TECNOLÓGICOS E DE INOVAÇÃO COM AS ROTAS TECNOLÓGICAS: APLICAÇÃO NA INDÚSTRIA TÊXTIL \& CONFECÇÃO
}

\author{
Germana Arcoverde Bezerra Zapata ${ }^{1}$ \\ Claudia Romani ${ }^{2}$ \\ Vanessa Venancio Pappetti Canhete ${ }^{3}$ \\ Tiago Schwingel Goulart ${ }^{4}$ \\ Ismar Henriques Silveira ${ }^{5}$ \\ Fábio Dutra ${ }^{6}$ \\ Juliano Anderson Pacheco ${ }^{7}$
}

\section{Resumo}

O panorama do setor industrial brasileiro apresenta um decréscimo econômico com perspectivas de recuperação em longo prazo. Com este cenário e na busca de apoiar o setor produtivo nacional no restabelecimento de seu crescimento, o Serviço Nacional de Aprendizagem Industrial - SENAI vem realizando diversas ações. Entre elas, destaca-se a implementação de Institutos de Tecnologia e de Inovação, cujos princípios são a disponibilização de infraestrutura física e de pessoas qualificadas orientadas à prestação de serviços tecnológicos e de inovação, por meio do oferecimento às indústrias de um portfólio diversificado com alto valor agregado e que possam propiciar o aumento da competitividade de seus negócios, independentemente dos seus portes e dos setores a que pertençam. Neste contexto, este estudo tem como objetivo avaliar a relação entre o portfólio de serviços tecnológicos e de inovação oferecidos pelo Instituto SENAI de Tecnologia correlato e as rotas tecnológicas do setor Têxtil, Vestuário e Design Catarinense. Para a realização do estudo, o método proposto se baseia na avaliação quantitativa e qualitativa do Capital Intelectual do Instituto. $\mathrm{O}$ resultado desta avaliação proporcionou a identificação do grau de relação entre o portfólio (oferta) oferecido pelo Instituto SENAI de Tecnologia e as rota tecnológicas (demandas) oriundas da Indústria Têxtil \& Confecção de Santa Catarina, uma vez que foram medidos as potencialidades e os aspectos do Instituto a serem melhorados para atender adequadamente às demandas desse setor entre 2015 e 2022.

Palavras-chave: Rotas Tecnológicas (Roadmapping). Capital Intelectual.

Método QQS (Qualidade, Quantidade e Sistemática). Portfólio de Serviços Tecnológicos e de Inovação. Indústria Têxtil \&

Confecção.

1 Mestre, e-mail: gzapata@dn.senai.br

2 Mestre, e-mail: claudia@sc.senai.br

3 Mestre, e-mail: vcanhete@cni.org.br

4 Graduado, e-mail: tiago7sg@gmail.com

5 Especialista, e-mail: ismar@sc.senai.br

6 Especialista, e-mail: fabio.dutra@sc.senai. br

7 Doutor, e-mail: jap@ fiesc.com.br

$* * *$ 


\section{INTRODUÇÃO}

O panorama do setor industrial brasileiro apresenta decrescimento econômico com perspectivas de recuperação em longo prazo (FIESC, 2015). Segundo dados da Federação das Indústrias de Santa Catarina - FIESC, em 2014, o Produto Interno Bruto - PIB catarinense é o sexto do Brasil, registrando PIB industrial de $\mathrm{R} \$ 50,3$ bilhões. Sua indústria de transformação é a quarta do país em quantidade de empresas e a quinta em número de trabalhadores. Com este cenário e na busca de apoiar o setor produtivo nacional no restabelecimento de seu crescimento, o SENAI vem investindo em diversas ações. Entre elas, uma importante ação é a implementação de Institutos de Tecnologia e de Inovação, cujos princípios são a disponibilização de infraestrutura física e de pessoas qualificadas orientadas à prestação de serviços tecnológicos e de inovação, por meio do oferecimento às indústrias de um portfólio diversificado, com alto valor agregado e que possam propiciar o aumento da competitividade de seus negócios, independentemente dos seus portes e dos setores a que pertençam.

Neste sentido, a FIESC com a missão de promover a competitividade da indústria catarinense de forma sustentável e inovadora, além de participar do Programa dos Institutos SENAI de Tecnologia e de Inovação, investiu em outra ação, como o Plano de Desenvolvimento Industrial Catarinense - PDIC, iniciado em 2012 e com previsões de atuação até 2022. Esse programa contempla ações de curto, médio e longo prazo para o Estado, a fim de situar Santa Catarina em posição competitiva de destaque nos cenários nacional e internacional. (FIESC, 2014).

\section{O Programa COMPREEnde}

TRÊS GRANDES PROJETOS:

Setores Portadores de

Futuro, Rotas Estratégicas

SETORIAIS PARA A INDÚSTRIA

Catarinense Até 2022 E

O Masterplan. Para isso,

VIU-SE A NECESSIDADE

DE ESTABELECER AÇÕES,

DISPONIBILIZAR RECURSOS,

IDENTIFICAR TENDÊNCIAS

TECNOLÓGICAS E ELABORAR

ESTRATÉGIAS POSSÍVEIS E

DESEJÁVEIS QUE ATENDESSEM

AOS SETORES PRIORIZADOS

(FIESC, 2014).

Entre esses setores, encontra-se o Setor Têxtil \& Confecções, com grande importância na indústria catarinense e brasileira. De acordo com os dados informados no PDIC 2022, em 2013, este setor correspondeu a 16\% do Valor Bruto da Produção Industrial - VBPI do total da indústria de transformação estadual e a 20\% do setor Têxtil \& Confecção brasileiro. Além disso, o segmento de confecção de artigos do vestuário e acessórios da indústria de Santa Catarina (SC) cresceu 6,4\% ao ano, acima da média brasileira, que foi de 3,0\% ao ano na mesma base de comparação. (FIESC, 2014).

Neste cenário, faz-se necessário que os portfólios de serviços tecnológicos e de inovação oferecidos pelos Institutos SENAI estejam alinhados às demandas da indústria nacional, 
para que estas solicitações possam ser atendidas adequadamente e da melhor maneira possível.

Diante do exposto, a temática deste estudo objetiva avaliar quanto o portfólio de serviços tecnológicos e de inovação do Instituto SENAI de Tecnologia está atendendo às demandas provenientes das rotas tecnológicas da indústria e quanto o Instituto está preparado para tal. Essa relação é obtida por meio da avaliação quantitativa, qualitativa e sistemática do Capital Intelectual do Instituto, que é quem executa o portfólio de serviços tecnológicos e de inovação.

Dessa forma, passa a ser relevante pelo fato de que não há um mecanismo sistematizado que apoie um Instituto na verificação de quais serviços por ele oferecidos à indústria estão realmente condizentes e estão satisfazendo a essas demandas.

Ao final deste estudo, o Instituto tem o cenário de posicionamento quanto às suas necessidades de melhoria e potencialidades em relação ao seu Capital Intelectual, assim como quais as rotas tecnológicas da indústria de diferentes portes que têm prioridade de atendimento e quais as regiões do estado em que se concentram essas indústrias demandantes.

A aplicação do método foi realizada no Instituto SENAI de Tecnologia Têxtil,Vestuário e Design de Santa Catarina, baseando-se nas demandas tecnológicas apresentadas pela Indústria Têxtil \& Confecção Catarinense e identificadas na pesquisa do PDIC 2022.

\section{ROTAS TECNOLÓGICAS, PLANEJAMENTO ESTRATÉGICO E CAPITAL INTELECTUAL}

O estudo de Roadmapping (Rotas Tecnológicas) designa um método de construção de perspectivas de futuro em um horizonte temporal predeterminado. É considerado um instrumento de apoio para conectar as estratégias de uma organização às ações futuras e sua incorporação no planejamento da empresa de tal forma que a infraestrutura, as competências e as tecnologias necessárias estejam disponíveis no momento adequado. Neste sentido, as rotas tecnológicas tornam-se reconhecidas como um método para identificar as demandas do mercado, ou seja, pelas inovações tecnológicas necessárias para que as empresas possam atender a mercados futuros. (WHALEN,2007; FELLOWS,2007; OZAKI, 2014; FIESC, 2014).
As Rotas Tecnológicas são traduzidas como efetiva ferramenta na elaboração de um planejamento estratégico, uma vez que, por meio dele, pode-se visualizar os possíveis caminhos de um negócio ou organização em direção aos seus objetivos de inovação, mostrando as oportunidades existentes e os desafios a serem enfrentados, o planejamento de prestação de serviços, o planejamento de programas de P\&D\&I e processos, assim como a promoção de avanços em determinada área e a identificação de ações estratégicas a serem realizadas. 


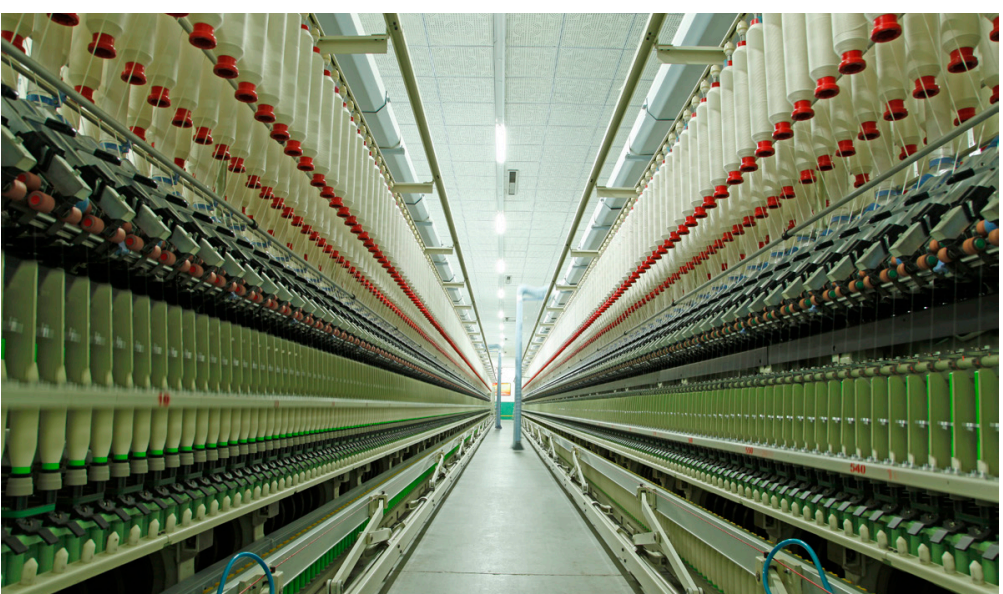

O planejamento estratégico contempla atividades, ferramentas, conceitos, ações, esforços que visam apoiar uma empresa na visão de mercado, melhorando oportunidades de negócio e a adaptação para possíveis remodelagens de empreendimentos, serviços e produtos (KOTLER, 1998; MACLEOD; LEÓN; ESQUIVIAS, 2001). Uma das atividades presentes em um planejamento estratégico e de grande importância em uma instituição é a gestão portfólios, de produtos ou de serviços, que são oferecidos pela empresa a um determinado mercado. Para que as organizações possam atender em sua plenitude às demandas do mercado referente,é necessário e primordial que, além de conhecer as demandas, a empresa conheça, selecione e identifique o portfólio que mais se adequa à situação.O "Portfólio é um conjunto de projetos ou programas e outros trabalhos, agrupados para facilitar o gerenciamento eficaz desse trabalho a fim de atingir os objetivos estratégicos de negócios"(PMBOK,2008).Assim,o estudo de um portfólio propicia grande contribuição aos dirigentes de uma empresa com a visibilidade das dimensões estratégicas que devem nortear seu balanceamento, assim como permitir a adequada priorização dos projetos/produtos/ serviços, como também identificar mecanismos de controle e até mesmo itens do portfólio que devam ser retirados/descartados ou remodelados (ANTUNES et al., 2012).
Outra atividade de extrema necessidade para a construção de um planejamento estratégico no contexto atual de mudanças e de complexa competitividade que enfrentam as empresas é o conhecimento sobre o seu Capital Intelectual, que é considerado a soma do capital humano e o capital estrutural. Este recurso é a base para que os empreendimentos possam adequar-se às contínuas transformações de seus ambientes de atuação. (KAPLAN \& NORTON, 1996; SVEIBY,1997;EDVINSSON \&MALONE, 1997; STEWART, 1998; BONTIS, 2000; BONTIS, 2001; VAZ, 2012).

\section{O SUCESSO DE UMA \\ ORGANIZAÇÃO REflETE SEU \\ PLANEJAMENTO ESTRATÉGICO E, \\ PARA ISSO, FAZ-SE NECESSÁRIO \\ CONHECER O AMBIENTE \\ INTERNO E EXTERNO EM QUE A \\ ORGANIZAÇÃO ESTÁ INSERIDA.}

Neste sentido, os métodos de avaliação do Capital Intelectual para este estudo, o InCaS (Intellectual Capital Statement), a metodologia QQS (Quality, Quantity and Systematic Management) e o método de avaliação por pares são desenvolvidos como ferramenta de análise do ambiente interno da instituição, que, no caso, é um Instituto SENAI de Tecnologia. Para o ambiente externo, são exploradas as análises das rotas tecnológicas definidas pelo PDIC 2022. Com isso, essas análises e avaliações são desenvolvidas até que se possa determinar qual a relação entre o ambiente externo (demandas da indústria) e interno da organização (portfólio de serviços técnicos, tecnológicos e de inovação), sendo refletida em um cenário que indique qual a melhor estratégia a ser seguida pelo Instituto. 


\subsection{Métodos de Análise/ Avaliação de Capital Intelectual $(\mathrm{Cl})$}

A literatura preconiza que são muitos os métodos utilizados para a avaliação e gestão do CI, dentre os quais se ressalta o Balance Scorecard, de Kaplan e Norton (1996) e o método Skandia Navigator, elaborado em 1994 (SVEIBY,1998; EDVINSSON, 2013).

Além desses, destacam-se os métodos referentes ao projeto europeu Intellectual Capital Statement - Made in Europe ( $\mathrm{InCaS}$ ) e o alemão Wissensbilanz - Made in Germany, desenvolvido pelo Instituto Fraunhofer IPK, de Berlin, e aplicado a pequenas e médias empresas alemãs (MERTINS; WILL, 2008). Ambos os métodos são baseados na análise do CI em três dimensões: Capital Humano, Capital Estrutural e Capital Relacional.

Entre as cinco etapas que compõem o método InCaS, encontra-se a aplicação da metodologia QQS (Quality, Quantity and Systematic Management), que será utilizada neste estudo, uma vez que as etapas anteriores já tinham sido realizadas em outros trabalhos utilizados pelo próprio SENAI e a metodologia foi considerada adequada.

\subsubsection{Aplicação do Método QQS}

O objetivo principal da metodologia QQS é apresentar o conjunto dos Fatores Críticos Operacionais, também conhecidos como Fatores Críticos de Sucesso (FCS), ou Portfólio que foram gerados na Etapa 2 e que serão analisados. A avaliação desses fatores, além de indicar a situação inicial em relação às forças e fraquezas do CI, contempla as análises qualitativas, quantitativas e sistemáticas de cada fator. Assim, essa avaliação deve estar alinhada ao planejamento estratégico da organização (MERTINS; WILL, 2008). Uma vez identificados e definidos os FCS, realiza-se então a votação, que consta da avaliação quantitativa, qualitativa e sistemática de cada fator. Para isso, utiliza-se a escala de 0 a 120\%, cujas notas significam: 0\% para avaliações consideradas insatisfatórias, 30\% quando o seu grau de desenvolvimento é parcialmente suficiente, $60 \%$ para as avaliações suficientes em grande parte, $90 \%$ para avaliações totalmente suficientes e $120 \%$ quando os fatores são mais utilizados do que o necessário ou mais investidos operacionalmente do que estrategicamente é necessário. Para a obtenção e compilação dos resultados da avaliação, utiliza-se o software WissensbilanzToolbox ("Caixa de Ferramentas - Capital Intelectual”) desenvolvido pelo Instituto FraunhoferIPK Berlim, da Alemanha, durante o projeto Wissensbilanz - Made in Germany e quadros e gráficos elaborados no MS Excel ${ }^{\circledR}$, que é a ferramenta utilizada neste estudo.

O penúltimo passo da aplicação é a análise de impacto dos FCS. Para isso, serão utilizadas a Pontuação de impacto e a Matriz de impacto cruzado. Nessa análise, a equipe estrutura a matriz e capta o grau de influência exercida dos fatores entre si, o que gera como resultado uma matriz de influência relativa. Para tal análise, a escala utilizada adota os seguintes valores: (0) para sem influência, (1) para fraca influência, (2) para forte influência ou (3) para influência exponencial de um fator de CI sobre outro (INCAS,2010). Como último passo da aplicação, serão realizadas a compilação e a discussão dos resultados, que é de grande relevância, pois é traçado o cenário atual do Capital Intelectual da organização que está sendo avaliada.

Após a aplicação da metodologia QQS, a organização que foi analisada tem condições de 
vislumbrar o cenário do seu Capital Intelectual, bem como quais são as suas potencialidades, fortalezas e os aspectos da instituição que requerem implementação de melhorias.

\section{MÉTODOLOGIA UTILIZADA NO ESTUDO}

Aidentificação do quanto um Instituto SENAI está preparado para atender às demandas provenientes da indústria nacional dá-se por meio da determinação da relação das rotas tecnológicas (demandas) da Indústria previamente identificadas com o portfólio de serviços tecnológicos e de inovação (oferta) de um Instituto SENAI correlato. Para isso, foi definida uma proposta metodológica que contempla as análises em relação ao portfólio de serviços, às rotas tecnológicas e ao Instituto, por meio da execução de três fases: Fase 1 - Priorização do Portfólio, Fase 2 - Priorização de Segmentos (p/Portes) da Indústria e a Fase 3 - Análise do Capital Intelectual, descritas a seguir, assim como representadas na Figura 1.

Figura 1: Método proposto para determinar a relação de rotas tecnológicas com portfólio de serviços tecnológicos e de inovação de um Instituto SENAI

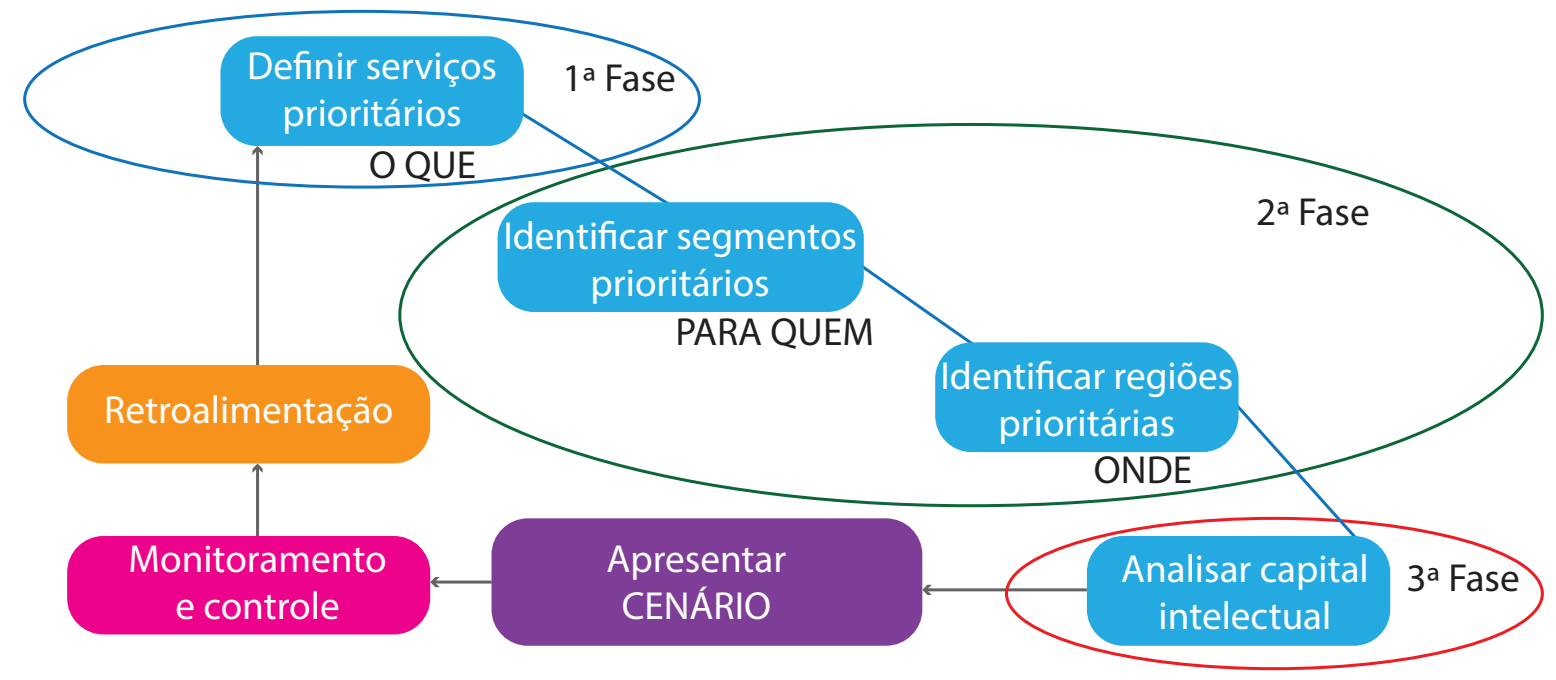

Fonte: Dos autores (2015)

\subsection{Fase 1: Priorização do Portfólio}

A Fase 1 descrita na Figura 1 é realizada durante o $1^{\circ}$ workshop e compreende a priorização do portfólio. Nesta fase, as análises realizadas identificam o grau de relação de cada serviço tecnológico e de inovação do portfólio com cada rota tecnológica previamente identificada. As análises e comparações são realizadas pelos especialistas, que, por consenso, definem o grau de relação, assim como os serviços a serem priorizados. 


\subsubsection{Etapa 1: Análise de Portfólio} (Ofertas) em relação às Demandas (Rotas Tecnológicas)

Na Etapa 1, o foco das análises é o portfólio de serviços tecnológicos e inovação em relação às rotas tecnológicas, compreendendo os seguintes objetivos: a) avaliar o grau de aderência dos serviços do portfólio de acordo com as tendências das tecnologias identificadas nas rotas tecnológicas; b) avaliar se o serviço atende às tecnologias; e c) identificar o grau em que as tecnologias têm as suas demandas atendidas pelos serviços. Estas análises são realizadas por meio das seguintes atividades: Atividade 1 definição do quadro de especialistas, Atividade 2 - tratamento dos dados das Rotas Tecnológicas de acordo com os segmentos/tecnologias identificadas e respectivas subclassificações, Atividade 3 - definição e classificação do portfólio a ser estudado em áreas de negócio do instituto a ser analisado, e Atividade 4 - análise por pares entre as tecnologias identificadas do instituto correlato. Todas as análises são realizadas pelos especialistas e que definem a classificação, por consenso das opiniões, assim como de acordo com suas respectivas experiências/práticas e os serviços mais prestados à indústria pelo Instituto.

\subsubsection{Etapa 2: Análise dos Serviços do Portfólio em relação à Receita Atual por Serviço}

Nesta etapa, o foco das análises é o portfólio de serviços tecnológicos e inovação em relação à receita por tipo de serviço. Esta etapa é realizada por meio das seguintes atividades: Atividade 1 - Identificação dos serviços que estão sendo vendidos pelo Instituto e suas respectivas receitas; Atividade 2 - Listagem dos serviços por ordem de maiorvalor de receita e Atividade 3-Comparação entre cada serviço do portfólio que gerou receita com cada serviço de acordo com o seu grau de aderência de atendimento a cada demanda.

Ressalta-se que, ao término da execução das Etapas 1 e2, obtêm-se a relação dos serviços do portfólio que serão a base do posicionamento do Instituto para o planejamento estratégico.

\subsection{Fase 2: Priorização de Segmentos (por Portes) da Indústria}

A Fase 2, descrita na Figura 1, realizada durante o $2^{\circ}$ workshop, compreende a priorização dos segmentos da indústria quanto ao seu porte em relação às tecnologias e quanto ao posicionamento geográfico das mesmas, compreendendo assim a duas etapas, respectivamente.

\subsubsection{Etapa 1: Priorização de} Segmentos (por Portes das Empresas) em relação às Rotas Tecnológicas

O foco é a classificação das empresas por Classificação Nacional das Atividades Econômicas - CNAE, por portes e por aderência de cada empresa classificada à tecnologia e compreende as seguintes atividades: Atividade 1- identificar as empresas por porte (Micro, Pequena, Média e Grande) estabelecidas no estado e relacionadas ao Setor, Atividade 2 - avaliar o grau em que os segmentos/portes são impactados pelas tecnologias. A avaliação do grau da relação faz-se por meio de votação dos especialistas, utilizando uma matriz de correlação. 


\subsubsection{Etapa 2: Priorização de}

Segmentos (por Portes Das

Empresas) em relação às Regiões do

Estado

Distribui-se as empresas classificadas na Etapa

2 nas regiões geográficas, identificando a localização dos segmentos (por porte das empresas) nas regiões do estado.

Essa priorização é importante para que o Instituto possa ter a noção de distância no momento do atendimento, assim como ao identificar o tipo/nome da empresa por porte, terá condições de mapear quais são as necessidades, por exemplo, de infraestrutura de laboratórios e de recursos humanos.

\subsection{Fase 3: Análise do Capital Intelectual do Instituto SENAI}

A Fase 3, descrita na Figura 1, realizada durante o $2^{\circ}$ workshop, compreende a avaliação do Capital Intelectual em três dimensões: capital humano, capital relacional e capital estrutural, cujo objetivo é de que se tenha, após a análise do CI do Instituto, por meio da aplicação do método QQS Assessment, condições de julgar se a sua equipe que oferece/executa o portfólio de serviços está adequada para seu pleno atendimento, se a equipe tem competência para oferecer tal portfólio e se o Instituto definiu de maneira adequada qual é a sua proposta de valor oferecida aos seus clientes.

\section{A EQUIPE AVALIA QUALITATIVA- \\ MENTE, QUANTITATIVAMENTE \\ E SISTEMATICAMENTE OS DIFE- \\ RENTES FATORES DO Cl: CH, \\ CE E O CR - SEMPRE PENSAN- \\ DO COMO ESTÃO HOJE E COMO \\ DESEJAM SER EM 2022.}

A votação não leva em consideração os níveis hierárquicos dos integrantes do grupo de especialistas. Todos votam e devem opinar sobre os processos, competências, relacionamentos etc. Isso é imprescindível para que se tenha como resultado final o que será necessário para que até 2022 o portfólio atenda às demandas da indústria. Após a votação, faz-se a avaliação da matriz de impacto, que, no caso, tratou da avaliação do grau de influência/relação de cada fator crítico com cada área de negócio do Instituto, por meio de uma matriz de correlação, diferenciando assim do método de Mertins e Will (2008), no qual a matriz de impacto mede o grau de influência/importância dos fatores críticos entre si.

Baseando-se em experiências de utilização do método, considera-se que o método aqui proposto oferece aos Institutos um mecanismo sistematizado e de melhoria contínua dos seus processos. Logo, sua aplicação em períodos predeterminados possibilitará que o Instituto sempre esteja atualizado quanto ao seu potencial em atender satisfatoriamente às demandas provenientes da indústria. 


\section{RESULTADOS DA APLICAÇÃO DO MÉTODO}

É apresentado o cenário atual do Instituto SENAI de Tecnologia Têxtil, Vestuário e Design à luz da avaliação do seu Capital Intelectual.

\subsection{Resultados das Fases}

1 e 2 - Análise de Portfólio (Ofertas) em relação às Demandas (Rotas Tecnológicas)

Essas etapas foram realizadas pela equipe de especialistas e tratam das análises de cada serviço do portfólio por área de negócio (Quadro 1) com cada classificação das tecnologias demandadas.

Análise Demanda em relação ao Portfólio de Consultoria

Os serviços analisados que compõem o portfólio em relação à consultoria estão descritos no Quadro 1.

Quadro 1: Serviços de consultoria componentes do portfólio do IST

\begin{tabular}{|c|c|}
\hline Análise do processo industrial e proposta de melhoria & Processo \\
\hline Melhoria do processo de fabricação têxtil & Processo \\
\hline Melhoria do processo de fabricação confecção & Processo \\
\hline Implantação de boas práticas para planejamento e controle de \\
produção & Processo e Produto \\
\hline Implantação de lean manufacturing & Processo \\
\hline Otimização dos custos & Processo \\
\hline Design estratégico & Produto e Conceito \\
\hline Designn de produto & Produto \\
\hline Planejamento e desenvolvimento de coleções & Produto \\
\hline Otimização de leiaute do processo produtivo & Processo \\
\hline Análise e melhoria da modelagem e construção do produto & Processo e Produto \\
\hline
\end{tabular}

Fonte: Dos autores (2015) 
Para as demandas de matéria-prima têm-se dois serviços com aderência (potencial para entrega de solução no item avaliado), respectivamente, melhoria do processo de fabricação têxtil e análise do processo industrial e proposta de melhoria.

Em relação ao processo, têm-se quatro serviços com forte aderência, respectivamente: implantação de boas práticas para planejamento e controle de produção, melhoria de processo de fabricação de confecção, análise do processo industrial e proposta de melhoria e melhoria do processo de fabricação têxtil.

Em relação ao produto, a média e a baixa aderência prevalecem em todos os seus serviços.

Em relação ao conceito, dá-se destaque aos serviços, respectivamente, planejamento e desenvolvimento de Coleções, que demonstra ter média aderência, enquanto que os demais serviços têm baixa ou nenhuma aderência para atender às demandas tecnológicas.

Análise Demanda Atual com a Demanda Potencial (Consultoria - Receita)

Em relação à demanda atual, observou-se que o serviço Melhoria do Processo de Fabricação em
Confecção demandado pelas empresas é o produto que gera mais receitas para o Instituto.Em relação à demanda potencial, há dois aspectos a serem avaliados.

Primeiro: serviços que estão no atual portfólio e não apresentam receita significativa, pois, para realizá-los, o Instituto apresenta carência de capital intelectual. Neste sentido, destacam-se os seguintes serviços: Processo de Fabricação Têxtil; Design Estratégico; Design de Produto. Segundo: serviços que não estão no portfólio e poderiam ser inseridos, porém com o desenvolvimento de competências. São exemplos os seguintes os serviços: ecodesign, design de moda e design de comunicação.

O processo fabricação têxtile boas práticas para PCP (Planejamento e Controle de Produção) foram priorizados pela aderência e não pela receita.

Análise Demanda em relação ao Portfólio de Metrologia

Para análise de aderência do portfólio da metrologia, foram analisados os serviços descritos no Quadro 2. 


\begin{tabular}{|l|}
\hline Microscopia eletrônica \\
\hline Determinação de resistência à tração e ao alongamento de tecidos planos \\
\hline Costurabilidade em tecido plano e de malha \\
\hline Determinação de alteração dimensional e torção \\
\hline Ensaios de solidez de cores \\
\hline Medições de cores via espectrofotômetro \\
\hline Determinação de pilling - métodos caixa e martindale \\
\hline Determinação da composição quantitativa e qualitativa de fibras \\
\hline Determinação de estrutura e densidade de tecidos \\
\hline Análise de defeitos em têxteis e confeccionados \\
\hline Ensaios em fibras de algodão \\
\hline Ensaios em fios têxteis, tecidos e malhas, artigos têxteis hospitalares. \\
\hline Formaldeído e flamabilidade \\
\hline Ensaios em fibras \\
\hline Ensaios em fios têxteis, tecidos e malhas, artigos têxteis hospitalares. \\
\hline Xenoteste, microscopia e ponto de fusão de fibras. \\
\hline Interlaboratorial físico em têxteis \\
\hline Interlaboratorial químico em têxteis \\
\hline
\end{tabular}

Fonte: Dos autores (2015)

Para demandas de matéria-prima, o portfólio de serviços tem forte aderência (potencial para entrega de solução no item avaliado), com destaque para:interlaboratorial físico em têxteis, formolaldeído e flamabilidade, determinação de pilling-métodos caixa e martindale, ensaios de solidez de cores, costurabilidade em tecido plano e de malha e microscopia eletrônica.

Em relação ao processo, prevalecem os serviços de metrologia.
No quesito de produto, $100 \%$ dos ensaios oferecidos tem forte aderência (potencial para entrega de solução no item avaliado).

Análise Demanda Atual em relação à Demanda Potencial (Metrologia - Receita)

Pôde-se observar que os serviços de metrologia, respectivamente, ensaios em fibras e ensaios em 
fios têxteis, concentraram $60 \%$ da receita do período de janeiro de 2014 a junho de 2015.

Quanto à demanda atual, cabe ressaltar que há manifestações de algumas empresas por ensaios que o instituto não oferece por carência no seu capital estrutural. A inserção de alguns destes produtos no portfólio exige alguns investimentos.

Pode-se citar como demanda atual não atendida os seguintes ensaios: testes em tecidos com proteçãoUV; permeabilidade ao ar,vapor e água; toxicidade em tecidos; snagging test (teste em tecidos para avaliar a resistência ao puxamento de fios); teste de estouro em malha (bursting test). Em relação à demanda futura, o serviço previsto é microbiologia em têxteis.

\section{Análise Demanda em relação ao} Portfólio De Inovação

Para identificar a aderência do portfólio de inovação, foram analisadas as pesquisas desenvolvidas no Instituto e se verificou a seguinte aderência (potencial para entrega de solução no item avaliado): matéria-prima (100\%), produtos (100\%), processos (88\%) e conceito $(22 \%)$.

Cabe destacar os projetos que foram desenvolvidos pelo instituto de acordo com as plataformas tecnológicas de atuação (Quadro 3).

Quadro 3: Projetos de Inovação ${ }^{1}$ desenvolvidos pelo Instituto

\begin{tabular}{|c|c|c|c|c|}
\hline Projeto & Empresa & $\begin{array}{c}\text { Porte da } \\
\text { Empresa }\end{array}$ & $\begin{array}{c}\text { Grau de } \\
\text { Inovação }\end{array}$ & Plataforma Tecnológica \\
\hline A & A & Médio & Ruptura & $\begin{array}{c}\text { Confecção do Vestuário, } \\
\text { Tecnologia Têxtil }\end{array}$ \\
\hline B & B & Pequeno & Ruptura & Tecnologia Têxtil \\
\hline C & C & Pequeno & Visionário & Tecnologia Têxtil \\
\hline
\end{tabular}

Fonte: Dos autores (2015)

Figura 2: Distribuição dos projetos de inovação conforme receita, aderência, grau de inovação e nível de competências
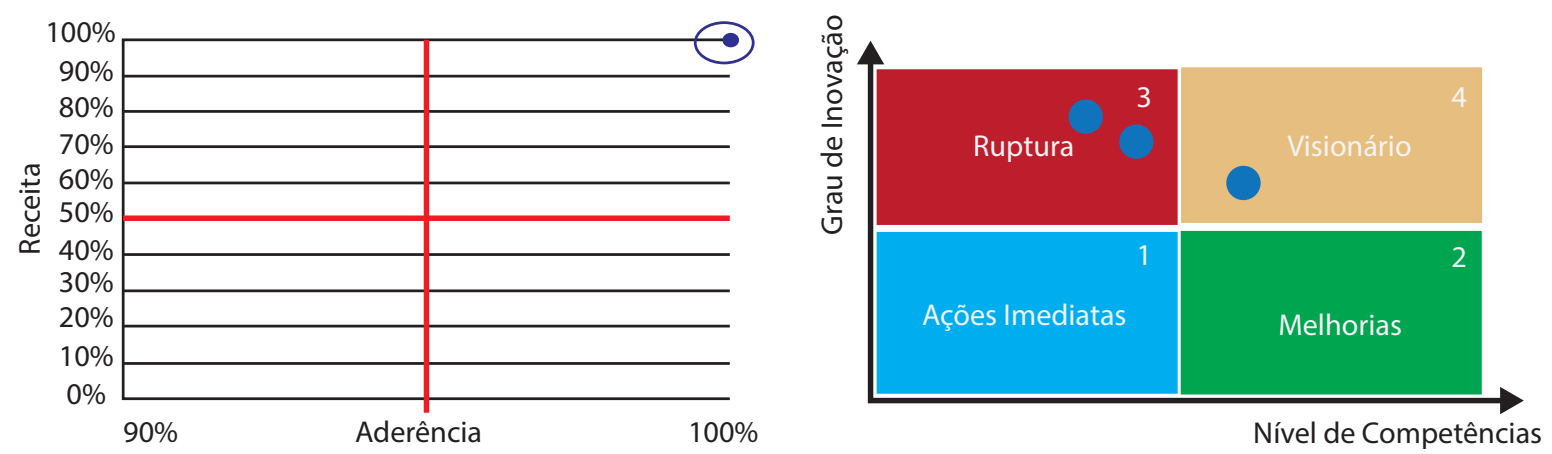

Fonte: Dos autores (2015)

\footnotetext{
${ }^{1}$ Os títulos dos projetos e os nomes das empresas envolvidas não constam na Quadro 3, por serem informações sigilosas.
} 
A Figura 2 compreende o gráfico da esquer$\mathrm{da}$, que mostra que a concentração dos projetos de inovação desenvolvidos pelo IST tem total aderência às demandas tecnológicas e correspondem aos projetos de rupturas e visionários, conforme descrição no Quadro 4, cuja classificação e detalhamento dos projetos foram propostos pela equipe de especialistas. A comprovação desta aderência se dá pelo tipo de projeto com a demanda do setor.

O gráfico da direita mostra a distribuição dos projetos de inovação desenvolvidos pelo IST, que são classificados em quatro categorias, conforme detalhamento apresentado na Figura 2.

Quadro 4: Legenda dos Tipos de Projetos

\begin{tabular}{|c|c|c|}
\hline N. ${ }^{\circ}$ & Item & Detalhamento \\
\hline 1 & $\begin{array}{l}\text { Projetos } \\
\text { Azuis }\end{array}$ & $\begin{array}{l}\text { Os projetos azuis (também chamados de ações imediatas) são caracterizados por } \\
\text { serem projetos simples, de curto prazo e sem riscos. Requerem poucos recursos, } \\
\text { são fáceis de executar e não encontram resistência para o seu desenvolvimento. }\end{array}$ \\
\hline 2 & $\begin{array}{l}\text { Projetos } \\
\text { Verdes }\end{array}$ & $\begin{array}{l}\text { Os projetos verdes (também chamados de projetos de melhoria) são } \\
\text { caracterizados pela melhoria de algo que já existe, objetivando a eliminação } \\
\text { de erros, desperdícios e atrasos, redução de custos e melhoria da qualidade. }\end{array}$ \\
\hline 3 & $\begin{array}{c}\text { Projetos } \\
\text { Vermelhos }\end{array}$ & $\begin{array}{l}\text { Os projetos vermelhos (também chamado de projetos de ruptura) são } \\
\text { caracterizados pela introdução de mudanças mais profundas, gerando uma } \\
\text { ruptura na maneira tradicional de fazer as coisas, criando novos conceitos e } \\
\text { novas tecnologias. Este tipo de projeto requer, também, novos conhecimentos, } \\
\text { habilidades e atitudes. }\end{array}$ \\
\hline 4 & $\begin{array}{l}\text { Projetos } \\
\text { Amarelos }\end{array}$ & $\begin{array}{l}\text { Os projetos amarelos (também denominados projetos visionários) são } \\
\text { caracterizados por realizarem uma mudança radical no que já é feito. São } \\
\text { projetos que alteram totalmentea forma, recursos, tempoe processos necessários } \\
\text { para realizar determinado produto ou serviço. Adicionalmente, possuem alto } \\
\text { custo de realização, muitos riscos e incertezas que demandam um longo prazo } \\
\text { para sua finalização. }\end{array}$ \\
\hline
\end{tabular}

Fonte: Dos autores (2015)

Análise Demanda Atual em relação à Demanda Potencial (Inovação - Receita)

Em relação à demanda atual, no ano de 2014, o negócio Inovação representou uma parcela importante na contribuição dos resultados financeiros para o Instituto. Pôde-se observar que, em função dos projetos anteriormente apresentados, o Instituto teve a geração de receita, com uma margem na ordem de $28,4 \%$, principalmente no item horas técnicas. Diante dos resultados, os projetos de pesquisa aplicada são fundamentais para a realização de novas prospecções.

O Instituto realizou 47 visitas (2014) às empresas, com foco na prospecção de projetos de inovação.Tais visitas não consolidaram parceria em projetos devido à dificuldade apresentada pelas empresas em prover contrapartidas de recursos financeiros, mesmo para projetos com recursos não reembolsáveis oferecidos por fontes de fomento que exigem contrapartida financeira por parte das empresas. 
Outra dificuldade enfrentada é a ausência de infraestrutura tecnológica suficiente para o desenvolvimento de pesquisas. Algumas empresas manifestaram o interesse em conhecer a estrutura laboratorial do Instituto dedicada à pesquisa e outras citaram a preocupação em realizar pesquisas em uma estrutura ainda em implantação.

\subsection{Resultados Fase 3}

\section{- Análise do Capital Intelectual}

$\mathrm{Na}$ sequência, são apresentados os resultados da Fase 3, que correspondem às análises quantitativas, qualitativas e sistemáticas do CI do IST estudado. Para isso, foram considerados os Fatores Críticos de Sucesso descritos no Quadro 5.

Quadro 5: Fatores Críticos de Sucesso (FCS) definidos

\begin{tabular}{|c|c|c|}
\hline Tipo & Item & Fator \\
\hline \multirow{5}{*}{$\begin{array}{l}\text { Capital } \\
\text { Humano }\end{array}$} & CH1.1 & Competência comunicativa dos funcionários (interna) \\
\hline & CH1.2 & Competência comunicativa dos funcionários (externa) \\
\hline & $\mathrm{CH} 2$ & Competência Técnica dos funcionários \\
\hline & $\mathrm{CH} 3$ & Competência Comportamental dos funcionários \\
\hline & $\mathrm{CH} 4$ & Habilidade de liderança \\
\hline \multirow{5}{*}{$\begin{array}{c}\text { Capital } \\
\text { Estrutural }\end{array}$} & CE1 & Portfólio de serviços aderente à indústria local \\
\hline & CE2 & Autonomia do gestor do Instituto \\
\hline & CE3 & Laboratórios equipados e certificados \\
\hline & CE4 & Otimização de processos e inovação \\
\hline & CE5 & Serviços executados em rede \\
\hline \multirow{4}{*}{$\begin{array}{c}\text { Capital } \\
\text { Relacional }\end{array}$} & CR1 & Relacionamento com empresas e clientes \\
\hline & CR2 & Relacionamento com parceiros estratégicos \\
\hline & CR3 & Relacionamento com fontes públicas de fomento \\
\hline & CR4 & Relacionamento interno - Sistema Indústria \\
\hline
\end{tabular}

Fonte: Dos autores (2015)

Como resultado geral obtido após a aplicação do QQS (análise Qualitativa, Quantitativa e Sistemática do CI), pode-se dizer que o Capital Intelectual do Instituto encontra-se, na sua grande maioria, apto a atender às demandas tecnológicas, no que se refere ao Capital Humano (que compreende as competências das pessoas em comunicação, técnica, comportamental e habilidade de liderança) e em relação ao Capital Estrutural (que compreende 
o portfólio de serviços, os laboratórios certificados, a otimização dos processos, a atuação em rede, a autonomia de gestão). Em relação ao Capital Relacional (que compreende o relacionamento das pessoas internamente ao instituto, externamente com os parceiros, clientes, com agentes de fomento, entre outros), obteve-se que este requer algum tipo de melhoria com diferentes graus de necessidades, que podem ser em quantidade,em qualidade ou em sistemática. Ressalta-se que, para a avaliação do CI, foi considerado entre os especialistas que os fatores que obtivessem valor igual ou superior a $60 \%$, então, estão aptos para atender às demandas da indústria do setor correlato. Já os fatores cujos resultados das análises encontram-se abaixo dos 60\%, embora atendam às demandas, eles possuem um maiorgrau de atenção ou requerem mais melhorias em seus respectivos processos.

Desta forma, na sequência, são descritos os resultados quantitativos, qualitativos e sistemáticos obtidos para cada tipo de fator crítico de sucesso analisado.

A análise quantitativa dos fatores críticos de sucesso permite avaliar se o volume do fator é suficiente para que os objetivos estratégicos do instituto sejam atendidos. Neste contexto, os fatores CE5 (Serviços executados em rede) e CR2 (Relacionamento com parceiros estratégicos) quantitativamente possuem percentua de $10 \%$, significando que a quantidade de projetos executados em rede não atende e que é necessário ter a informação de quais e quantos parceiros estratégicos devem estar conectados como IST, respectivamente.Têm-se que CH1.2 (Competência comunicativa dos funcionários (externa)), CH2 (Competência Técnica dos funcionários), CE1 (Portfólio de serviços aderente à indústria local), CE2 (Autonomia do gestor do Instituto), CE3 (Laboratórios equipados e certificados) possuem quantidade em $30 \%$, o que significa que existe elevada necessidade de melhoria em número de pessoas e que estas sejam mais comunicativas, com mais competências técnicas específicas, que tenham mais autonomia de gestão e requer mais equipamentos, como também novos serviços/produtos devem ser inseridos no portfólio, podendo assim, oferecer mais serviços que atendam ao maior número possível das demandas oriundas da indústria. Para os fatores críticos CH1.1 (Competência comunicativa dos funcionários (interna)), $\mathrm{CH} 3$ (Competência Comportamental dos funcionários), CH4 (Habilidade de liderança), CE4 (Otimização de processos e inovação) CR1 (Relacionamento com empresas e clientes) e CR3 (Relacionamento com fontes públicas de fomento) possuem quantidade em $60 \%$, significando que são bons, porém requerem melhorias em alguns casos em até $40 \%$ em quantidade de pessoas com mais habilidades de liderança,com mais competência comportamental, que tenham melhor relacionamento externo, principalmente com agentes de fomento e que a utilização dos processos existentes seja mais otimizada. Para o fator crítico CR4 (Relacionamento interno - Sistema Indústria), o percentual quantitativo é de $90 \%$, o que significa que está muito bom, ou seja, possui excelente relacionamento internamente no Sistema Indústria, quer seja entre as Unidades Operacionais estaduais e/ou em âmbito nacional, podendo ainda otimizar o benefício desse fator, assim como utilizar mais estrategicamente tal potencialidade.

A análise qualitativa dos fatores críticos de sucesso permite avaliar se a qualidade do fator analisado está coerente com o resultado obtido e o seu grau de influência para o alcance do objetivo. Neste sentido, a partir dos dados obtidos, observa-se que os fatores críticos de sucesso CE4 (Otimização de processos e inovação) e CR2 (Relacionamento com parceiros estratégicos) qualitativamente possuem 
percentual0.O CE4 (Otimização de processos e inovação), embora esteja bom em quantidade e como sua qualidade é zero, significa que existem métodos de gestão de projetos, porém não são processos certificados e reconhecidos por organismos certificadores. Entretanto, observou-se que, para o caso do Instituto estudado, não há necessidade desse fator ou a falta dele não influencia na obtenção de bons resultados. Para o CR2 (Relacionamento com parceiros estratégicos), como o grau de influência nos resultados é elevado, faz-se necessário identificar como o relacionamento com parceiros estratégicos pode influenciar positivamente em melhorias para o Instituto e para o atendimento à indústria de maneira geral. Têm-se que CH1.1 (Competência comunicativa dos funcionários (interna)), CH1.2 (Competência comunicativa dos funcionários (externa)), CE1 (Portfólio de serviços aderente à indústria local), CE2 (Autonomia do gestor do Instituto), CE3 (Laboratórios equipados e certificados), CR1 (Relacionamento com empresas e clientes) e CR3 (Relacionamento com fontes públicas de fomento) possuem qualidade em 30\%, significando que requerem uma atenção especial, pois tanto quantitativamente como qualitativamente encontram-se na faixa de melhoria de 40\% a 70\%, ou seja, interferem diretamente na obtenção dos resultados esperados e influenciam no planejamento estratégico do instituto. Os fatores críticos $\mathrm{CH} 2$ (Competência Técnica dos funcionários), $\mathrm{CH} 3$ (Competência Comportamental dos funcionários), $\mathrm{CH} 4$ (Habilidade de liderança) e CE5 (Serviços executados em rede) possuem qualidade em $60 \%$, significando que, embora atendam satisfatoriamente às demandas, o grau de influência nos resultados é elevado, requerendo assim monitoramento contínuo em relação às possibilidades de melhorias para esses fatores. Para o fator crítico CR4 (Relacionamento interno-Sistema Indústria), cujo percentual qualitativo é de $90 \%$, significa que, independentemente que esteja muito bom, como o seu grau de influência nos resultados esperados e nas estratégias a serem planejadas para o Instituto é elevado, requer monitoramento.

A análise sistemática dos fatores críticos de sucesso permite que seja identificada a existência ou não ou em que grau se encontra a padronização/sistematização dos processos do Instituto. A sistematização dos processos também influencia diretamente a obtenção dos objetivos estratégicos e o alcance das metas do Instituto.

Observou-se que os fatores críticos de sucesso CR3 (Relacionamento com fontes públicas de fomento) e CR4 (Relacionamento interno Sistema Indústria) sistematicamente possuem percentua de $10 \%$, significando que existe uma fortíssima necessidade de que o Instituto tenha um mapeamento das diversas fontes de fomento para subsidiar projetos e que existe uma necessidade de planejamento para fortalecer a atuação do Instituto nas redes e no compartilhamento de ações com outras entidades do Sistema Indústria, inclusive o SENAI DN. Têm-se que CH1.1 (Competência comunicativa dos funcionários (interna)), CH1.2 (Competência comunicativa dos funcionários (externa)), $\mathrm{CH} 2$ (Competência Técnica dos funcionários), $\mathrm{CH} 3$ (Competência Comportamental dos funcionários), CH4 (Habilidade de liderança), CE1 (Portfólio de serviços aderente à indústria local), CE4 (Otimização de processos e inovação), CE5 (Serviços executados em rede), CR1 (Relacionamento com empresas e clientes) e CR2 (Relacionamento com parceiros estratégicos) possuem sistemática em 30\%, o que significa que, embora se encontrem bem em 
quantidade e que seu grau de influência é alto, existe uma elevada necessidade de padronização dos processos vinculados a cada fator. Para o CE3 (Laboratórios equipados e certificados), cuja sistemática está também na ordem de 30\%, requerendo padronização para os processos relacionados, este fator não é de importância para o Instituto. Assim, não requer esforços para seu desenvolvimento.E, para o fator crítico CE2 (Autonomia do gestor do Instituto), a sistemática está em 60\%, significando que seus respectivos processos estão bons, requerendo melhorias em padronização dos processos, porém com menor intensidade que os demais.
Os resultados das análises em relação ao grau de influência dos fatores críticos nas linhas de negócio, respectivamente, Consultoria, Metrologia e Inovação (utilizando o potencial de melhoria para as respostas qualitativas, quantitativas e sistemáticas) estão apresentados no Gráfico 1. Nesta, o gráfico apresenta que, quanto mais para a esquerda e mais alta estiver a bolha, maior é a importância do fator crítico na área de negócio e maior é a necessidade de melhoria do fator. Quanto menor for o tamanho da bolha, maior é a necessidade de sistematização do fator.

\section{Gráfico 1: Grau de influência dos fatores críticos nas linhas de negócio: Consultoria, Metrologia e Inovação}
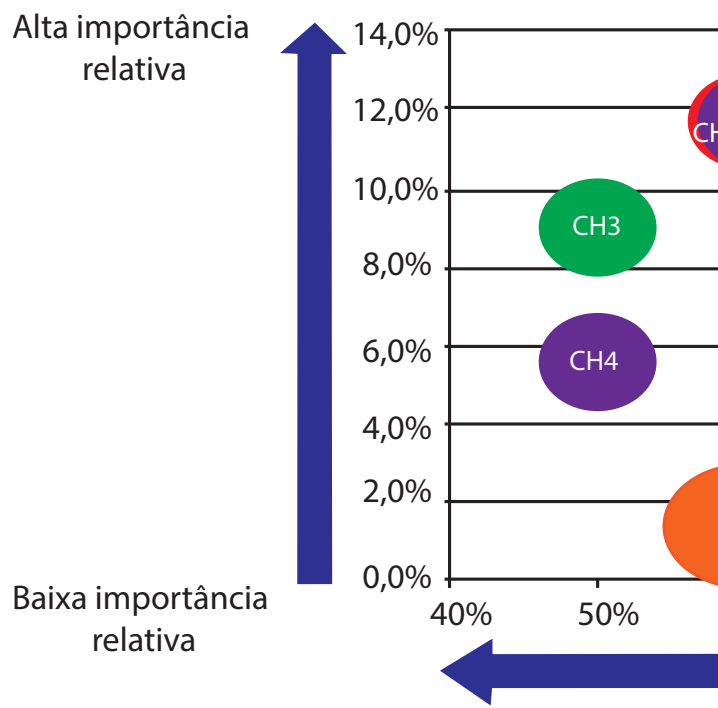

Alto potêncial de melhoria

\section{CR1}
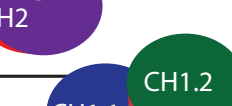

\section{1}
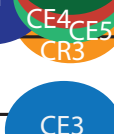

CE3

CE1

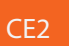

CE2

$60 \%$

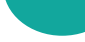

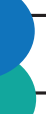

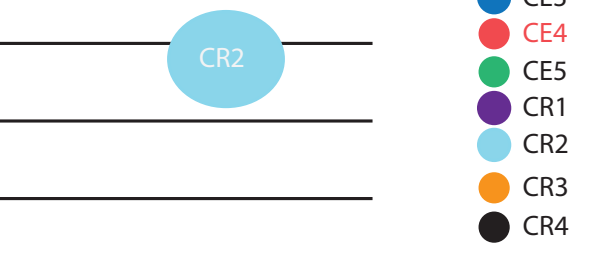

$\mathrm{CH} 1.1$

$\mathrm{CH} 1.2$

$\mathrm{CH} 2$

$\mathrm{CH} 3$

$\mathrm{CH} 4$

CE1

CE2

CE3

CE4

CE5

$\mathrm{CR} 2$

CR4

Fonte: Dos autores (2015)

A partir deste gráfico, há considerações sobre alguns valores/posicionamentos dos fatores críticos.

1. Como os valores de $\mathrm{CH} 2$ (Competência Técnica dos funcionários) = CR1(Relacionamento com empresas e clientes), então as bolhas estão sobrepostas. Ambos possuem elevada importância relativa sobre as áreas de negócio e possuem alto potencial de melhoria.

2. Como os valores de CE4 (Otimização de processos e inovação $)=$ CE5 (Serviços executados em rede), então as bolhas estão sobrepostas. Ambos possuem elevada importância relativa sobre as áreas de negócio 
e possuem potencial de melhoria na ordem dos $30 \%$.

3. Como o valor de sistemática de CR3 (Relacionamento com fontes públicas de fomento) $=0$ = CR4 (Relacionamento interno - Sistema Indústria), então as bolhas não aparecem no gráfico. Ambos possuem o grau de influência sobre as áreas de negócio muito elevado.

Quanto mais perto (mais à esquerda) e mais alta estiver a bolha, mais potencialidade de melhoria possui e mais influência o fator exerce nas linhas de negócio. Neste sentido, em ordem decrescente, conforme demonstrado, têm-se primeiro a sequência do grau de influência de cada fator nas linhas de negócio: CR2 (Relacionamento com parceiros estratégicos), CH3 (Competência Comportamental dos funcionários), $\mathrm{CH} 1.1$ (Competência comunicativa dos funcionários (interna)), CE4 (Serviços executados em rede) = CE5 (Serviços executados em rede), $\mathrm{CH} 4$ (Habilidade de liderança), CE3 (Laboratórios equipados e certificados), CR2 (Relacionamento com parceiros estratégicos), CE1 (Portfólio de serviços aderente à indústria local), e CE2 (Autonomia do gestor do Instituto). E, como segundo resultado, têm-se, também em ordem decrescente, a sequência em relação ao potencial de melhoria dos fatores críticos nas linhas de negócio: $\mathrm{CH} 4$ (Habilidade de liderança) = $\mathrm{CH} 3$ (Competência Comportamental dos funcionários) $=50 \%, \mathrm{CE} 2$ (Autonomia do gestor do Instituto) $=\mathrm{CR} 2$ (Relacionamento com parceiros estratégicos) $=40 \%, \mathrm{CH} 1.1$ (Competência comunicativa dos funcionários (interna) $=35 \%$, CE4 (Otimização de processos e inovação) = CE5 (Serviços executados em rede) = CE 3 (Laboratórios equipados e certificados) $=\mathrm{CE} 1$ (Portfólio de serviços aderente à indústria local) $=30 \%$, CR2 (Relacionamento com parceiros estratégicos) $=10 \%$.

O Gráfico 2 representa a análise de importância conjunta das três dimensões do CI e o potencial de melhoria de cada uma em relação às áreas de negócio.

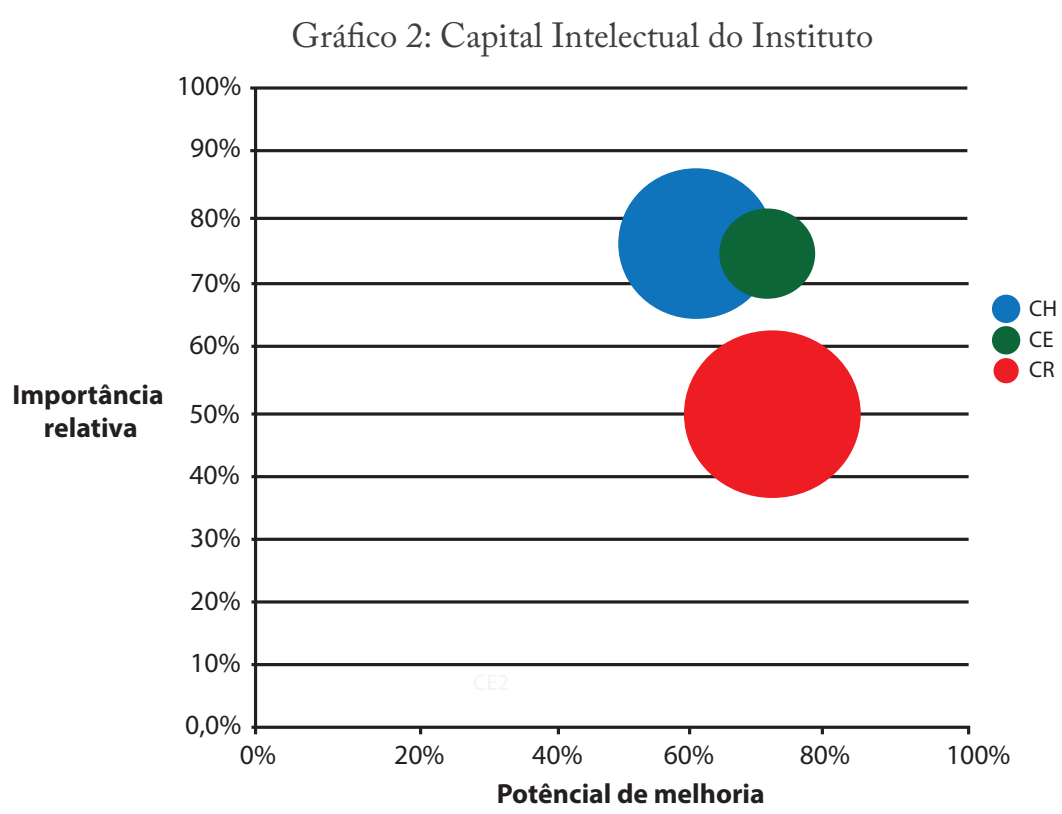

Legenda:

CH - Capital Humano: Oportunidade de Melhoria em relação à demanda futura;

CE - Capital Estrutural: Oportunidade de melhoria e relevância para os negócios inovação e metrologia;

CR - Capital Relacional: Oportunidade de melhoria em relação ao trabalho em rede e aproximação com entidades parceiras.

Fonte: Dos autores (2015) 


\subsection{Cenário para Posicionamento do IST}

Após todas as análises desenvolvidas durante a aplicação do método, foi possível a obtenção do cenário atual do IST em relação ao quanto este está preparado com recursos humano e estrutural para atender às demandas tecnológicas em curto, médio e longo prazo, considerando a linha temporal até 2022. Neste sentido, nesta seção, apresenta-se o resumo do cenário das prioridades a serem realizadas em curto prazo pelo IST Têxtil, Vestuário e Confecção em relação às suas áreas de negócio: Consultoria, Metrologia e Inovação, destacando o(s) tipo(s) de serviço(s) a ser(em) priorizado(s), os segmentos das empresas envolvidas (CNAEs) e seus respectivos portes e as regiões a serem atendidas. Ressalta-se que foram consideradas todas as análises realizadas, como o grau de relação entre o Capital Intelectual do IST com cada serviço componente do portfólio, o grau de relação de atendimento de cada serviço com as demandas provenientes das rotas tecnológicas, o grau de influência do CI nas áreas de negócio e quais os segmentos das empresas e respectivos portes que serão tidos como prioritários em atendimento pelo IST.

- Cenário para a área de negócio Consultoria do IST.

Para a área de negócio Consultoria, os serviços prioritários são três: melhoria do processo de fabricação têxtil, implantação de boas práticas para PCP, melhoria do processo de fabricação e confecção. Estes serviços atenderão às seguintes demandas provenientes da indústria: matéria-prima: fibras, corantes e aditivos; Processo: plasma a frio, adsorção, fotocatálise, poa, ozônio, bioprocessos, estamparia digital, nanotecnologia, impressão 3D; e Produto: tecidos tecnológicos (tecidos técnicos e tecidos inteligentes).
Os segmentos da indústria prioritários são as empresas de confecção, que sejam de micro e pequeno porte, localizadas principalmente nas regiões do Vale do Itajaí, Sul e Norte Catarinense. Os produtos que estão atualmente direcionados, em sua maioria, para confecções de micro e pequeno portes são "implantação de boas práticas para PCP" e "Melhoria do processo de fabricação confecção". O produto "melhoria do processo de fabricação têxtil" é mais direcionado para médias e grandes empresas do setor. Contudo, este não é oferecido atualmente por falta de capital intelectual (principalmente humano).

- Cenário para a área de negócio Metrologia do IST

Para a área de negócio Metrologia, os serviços prioritários são dois: ensaios em fibras e ensaios em fios têxteis. Estes serviços atenderão às seguintes demandas provenientes da indústria: Matéria-prima: fibras, corantes e aditivos; Processo: bioprocessos, estamparia digital, nanotecnologia,impressão 3D; e Produto: tecidos tecnológicos (tecidos técnicos e tecidos inteligentes). O segmento da indústria prioritário é o têxtil e de confecção, cujas empresas estejam localizadas principalmente nas regiões Norte e no Vale do Itajaí, em Santa Catarina.

- Cenário para a área de negócio Inovação do IST

Para a área de negócio Inovação, o serviço prioritário é o referente à pesquisa aplicada para desenvolvimento de processos e produtos inovadores. Este serviço estará atendendo as seguintes demandas provenientes da indústria: Matéria-prima: fibras, corantes e aditivos; Processo: plasma a frio, adsorção, fotocatálise, poa, ozônio, bioprocessos, estamparia digital, nanotecnologia, impressão 3D; Produto: tecidos tecnológicos (tecidos técnicos 
e tecidos inteligentes); e Conceito: Ambiente da inovação/PD\&I e Patrimônio imaterial. Os segmentos da indústria prioritários são as empresas têxteis e acabamento, de todos os portes, localizadas principalmente nas regiões do Vale do Itajaí e Norte Catarinense.

\section{CONCLUSÕES}

Um dos principais aspectos motivadores para a realização deste trabalho foi a necessidade de identificar se o portfólio de serviços tecnológicos e de inovação oferecido por um Instituto SENAI está alinhado às demandas provenientes do setor industrial, assim como, por meio da análise do Capital Intelectual daquele instituto, verificar o quão este está preparado com Capital Humano,Estrutural e Relacional para atender à indústria em uma determinada linha temporal.

\section{Ao término deste estudo, identificou-se que o portfólio dos serviços tecnológicos oferecido pelo Instituto está adequado às demandas tecnológicas do setor Têxtil, Vestuário e Design Catarinense, e o capital intelectual está apto para a prestação de serviços que o Instituto oferece.}

O método utilizado, contemplando as metodologias QQS e Roadmap, mostrou-se efetivo, pois, a partir dele, foi possível conectar as estratégias de atuação do Instituto e identificar quais as ações que deverão ser incorporadas no seu planejamento, de modo que a infraestrutura, as competências e as tecnologias necessárias estejam disponíveis no momento adequado para atender às demandas solicitadas. Ressalta-se a importância da utilização do QQS na análise dos pontos fortes e fracos do CI do Instituto, uma vez que a identificação desses pontos propiciou a visibilidade das dimensões estratégicas que deverão direcionar o balanceamento do portfólio, permitiu identificar qual a adequada priorização pelo Instituto dos projetos/produtos/serviços a serem desenvolvidos, como também identificou quais são os mecanismos de controle e padronização necessários para obom funcionamento do Instituto. Outro ganho com a aplicação do método proposto, não previsto inicialmente, foi que se elaborou, a partir dos dados gerados na pesquisa, um Simulador que permite avaliar a receita gerada com o portfólio atual do Instituto para cada segmento e projeções para ampliação da sua atuação.

Por fim, verificou-se que o método proposto passa a ser, para o Instituto, um mecanismo que apoia o planejamento das atividades, bem como contribui para o desenvolvimento do portfólio de serviços por ele oferecidos, indicando o quanto está preparado para atender o mercado. O método demonstrou, também, a possibilidade de replicabilidade em outras instituições ou empresas, assim como a sua utilização de forma sistemática resulte na apresentação de cenários para o reposicionamento dos Institutos em relação ao futuro das tecnologias/demandas apontadas pela indústria. 


\section{METHOD FOR DETERMINING THE RELATIONSHIP OF THE PORTFOLIO OF TECHNOLOGICAL SERVICES AND INNOVATION WITH THE TECHNOLOGICAL ROUTES: APPLICATION IN THE TEXTILE INDUSTRY AND CLOTHING}

\begin{abstract}
The panorama of the Brazilian industrial sector presents an economic decreased with recovery prospects in the long term. In this scenario and seeking to support national productive sector in the reestablishment of its growth, the National Service of Industrial Apprenticeship - SENAI has been working in several efforts and actions. Among them, we highlight the implementation of Institutes of Technology and Innovation, whoseprinciples are to provide of physical infrastructure and qualified specialists oriented to technological services and innovation, by offering to the industries a diversified portfolio with value-added services that might propitiate the increase of the competitiveness of their business, independently of their sizes and sectors which they belong to. In this context, this study aims to evaluate the relationship between the technological demands of the Textile, Apparel and Design of Santa Catarina with the portfolio of technological and innovation services offered by SENAI Institute of Technology. In order to carry out the work, the proposed method is based on the quantitative and qualitative evaluation of the Institute's Intellectual Capital. The result of this evaluation brought out the identification of the relationship degree between the portfolio (offer) provided by SENAI Institute of Technology and the demands from the Textile and Apparel Industry of Santa Catarina, since the potential and aspects of the Institute were measured to be improved in order to adequately meet the demands of this sector between 2015 until 2022.
\end{abstract}

Keywords: Technological Demands

(Roadmapping), Intellectual

Capital, QQS Method (Quality,

Quantity and Systematics),

Portfolio of Technological Services

and Innovation, Textile and

Apparel Industry.

\section{REFERÊNCIAS}

ANTUNES, P.H.; LOOS, M. J.; MIGUEL, P. A. C. Portfólio no Desenvolvimento de Novos Produtos: uma Análise das Publicações em Periódicos Nacionais. Revista de Gestão e Projetos - GeP. São Paulo, v. 3, n. 1, p. 50-71, jan./abr., 2012.

BONTIS, N. Managing organizational knowledge by diagnosing intellectual capital: framing and advancing the state of the field. International Journal of technology management. London, v. 18, n. 5, p. 433-462, 1999.

EDVINSSON, L. IC 21: Reflections from 21 years of IC practice and theory. Journal of Intellectual Capital.v. 14, n. 1, p. 163-172, 2013.

FELLOWS FILHO, L. Mapas de Rotas

Tecnológicas: roadmaps conceitos, tipos e etapas de elaboração. São Paulo: Atlas, 2007.

FIESC. Santa Catarina Industrial. 2014.

Disponível em: <http://zip.net/bwtxg8>. Acesso em: 2 maio 2015.

INCAS (Org). InCaS: Intellectual Capital Statement - Made in Europe. European Comission, DG Research, 2010. (European ICS Guideline). Disponível em: <http://zip.net/bltxjP $>$. Acesso em: 28 ago. 2015.

KAPLAN, R.; NORTON, D. P. The Balanced Scorecard. Harvard Business School Press. 1996.

KONG, E.; THOMSON, S. B. An intellectual capital perspective of human resource strategies and practices. Knowledge Management Research in Practice. v. 7, p. 356-364, 2009.

KOTLER, Philip. Administração de Marketing: análise, planejamento, implementação e controle. 5 . ed. . São Paulo: Atlas, 1998. 
MACLEOD, P.; LEÓN, P.; ESQUIVIAS, P. Planejamento Estratégico e Financeiro Integrado. Arlington: The Nature Conservancy, 2001.

MERTINS, K.; WILL, M. Strategic Relevance of Intellectual Capital in European SMEs and Sectoral Differences.: InCaS: Intellectual Capital Statement - Made in Europe. In: EUROPEAN CONFERENCE ON KNOWLEDGE MANAGEMENT, 9., 2008, Southampton. Proceedings.... . 2008. pp. 505-514.

\section{NADAI, P. B. D. Proposta para Determinar o} Índice de Competitividade dos Institutos SENAI de Tecnologia. 2014. 70 f. Dissertação (Mestrado) - Pós-graduação em Engenharia Aeronáutica e Mecânica, Instituto Tecnológico de Aeronáutica, São José dos Campos, 2014.

NADAI, P. B. D. et al. Relatório de avaliação da maturidade dos Institutos SENAI de Tecnologia. Brasília, 2014.

OZAKI, Adalton Masalu. Um estudo sobre a elaboração de roadmaps tecnológicos em empresas brasileiras de software. 2014. 208 f. Tese (Doutorado) - Curso de Administração, Departamento de Administração, Universidade de São Paulo, São Paulo, 2014.

Rotas estratégicas setoriais para a indústria catarinense 2022: Têxtil \& Confecção Florianópolis: FIESC, 2014. Disponível em: <http:// zip.net/bjtxJ4>. Acesso em: 1 maio 2015.

PROJECT MANAGEMENT INSTITUTE

- PMI. Um Guia do Conhecimento em Gerenciamento de Projetos: Guia PMBOK. 4. ed. EUA, 2008.
SENAI/SC. Portfólio Instituto SENAI de Tecnologia Têxtil, Vestuário e Design. 2012.

SVEIBY, K. E. The Intangible Assets Monitor. Journal of Human Resource Costing \& Accounting. v 2, p. 73-97, 1997.

SIGA (Sistema Integrado de Gestão de Arrecadação) / ACARC - Área Corporativa de Arrecadação CNI - DSC, 2015

STEWART, Thomas A. Capital Intelectual: a nova vantagem competitiva das empresas. 10. ed. Rio de Janeiro: Campus, 1998.

VALLEJOS, R.; GOMES, J. Applying a benchmarking methodology to empower a virtual organization. In: IFIP INTERNATIONAL CONFERENCE ON INFORMATION TECHNOLOGY FOR BALANCED AUTOMATION SYSTEMS IN MANUFACTURING AND SERVICES, 6. 2005, Proceedings... . 2005.

VAZ, Caroline Rodrigue at al. Análise bibliométrica da produção científica do conceito de capital intelectual (1980-2012). 2012. Disponível em <http://zip.net/bjtxJ6>. Acesso em: 15 abr. 2015.

WHALEN, Philip. J. Strategic and technology planning on a roadmapping foundation. Research Technology Management, v. 50, n. 3, 2007.

Data de recebimento: 18/10/2016

Data de aprovação: 13/12/2016 


\section{SOBRE OS AUTORES}

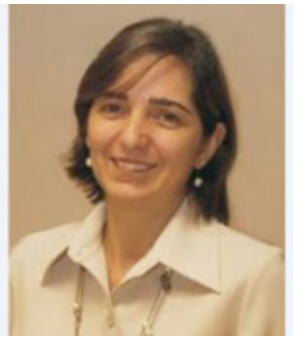

\section{Germana Arcoverde Bezerra Zapata}

Graduada em Engenharia de Alimentos pela Universidade Federal da Paraíba (1992), mestre em Engenharia pelo Instituto Tecnológico de Aeronáutica - ITA (SJC SP) (2015). Especialização em Agente de Inovação e Difusão Tecnológica. Tem experiência na área de controle de qualidade de alimentos em supermercadose, desde 2009 até o momento, atua na Unidade de Inovação e Tecnologia do SENAIDN como analista deDesenvolvimento Industrial,em gestão de projetos tecnológicos e de inovação. Foi coordenadora, durante 1 ano, da Rede SENAI de Logística.

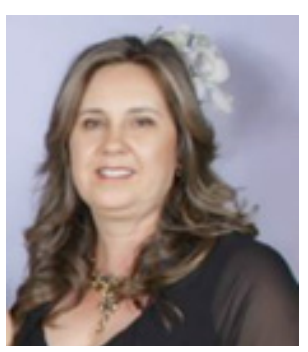

\section{Claudia Romani}

Mestre em Administração pela Universidade Federal de Santa Catarina. Especialista em Information System and Networks pela Ryerson International (Canadá) e em Marketing da Informação pela Universidade Federal de Santa Catarina. Graduada em Biblioteconomia pela Universidade Federal de Santa Catarina. Gestora do PMO do SENAI/SC.

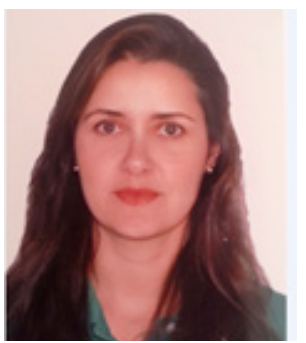

\section{Vanessa Venancio \\ Pappetti Canhete}

Graduada em Engenharia Química pela Universidade de Campinas (2003) e mestre em Engenharia peloInstituto Tecnológico de Aeronáutica (2015). Especialização em Administração Industrial pela Universidade de São Paulo. Nove anos de experiência atuando em indústrias de grande porte no desenvolvimento e otimização de processos e gestão de projetos de inovação e tecnologia.Possui experiência também em gestão da qualidade e produção. Atualmente é especialista em desenvolvimento industrial na unidade de Inovação e Tecnologia no SENAI - Departamento Nacional, em Brasília.

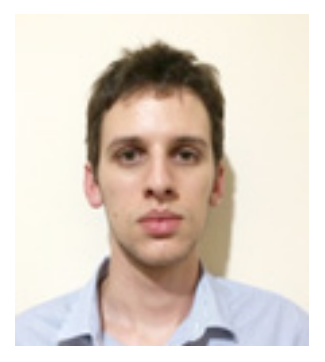

\section{Tiago Schwingel} Goulart

Engenheiro de produção formado pela Universidade de Brasília (UnB), com experiência nas áreas de gestão de projetos, planejamento estratégico, engenharia econômica e gestão da inovação. Atuou diretamente no planejamento, implantação e monitoramento dos Institutos SENAI de Tecnologia e de Inovação e conquistou a $2^{\text {a }}$ colocação do Grand Prix SENAI de Inovação 2014. Atualmente desenvolve análise de risco e controle de operações para o mercado financeiro.

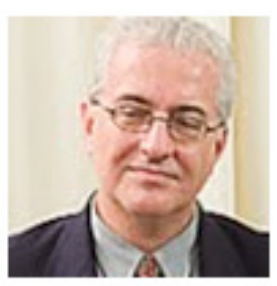

\section{Ismar Henriques}

\section{Silveira}

Graduado em Engenharia Mecânica pela Fundação Técnico Educacional Souza Marquez - FTESM / RJ. Pós-Graduado em Tecnologia da Soldagem pela Universidade Federal de Santa Catarina - UFSC Docente, Consultor e Especialista em Tecnologia no Departamento Regional do SENAI - SC. 


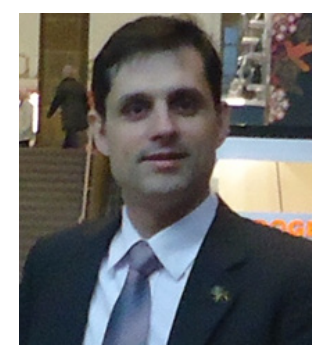

Fábio Dutra

Administrador e especialista em Engenharia de Produção pela Universidade Regional de Blumenau (FURB), especialista em gestão estratégica empresarial pelo Instituto Catarinense de Pós-Graduação (ICPG). Foi consultor e instrutor empresarial em gestão da produção e de negócios. Atuou como gerente do Instituto SENAI de Tecnologia Têxtil, Vestuário e Design. Atualmente é Gerente Administrativo na empresa Polpa Brasil Desidratados Ltda.

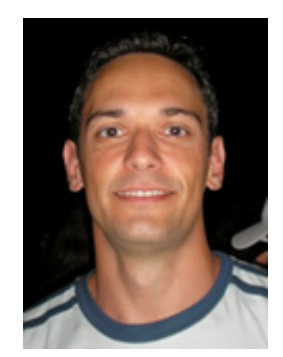

Juliano Anderson Pacheco

Engenheiro Eletricista graduado pela Universidade Federal de Santa Catarina (UFSC), mestre em Ciências da Computação, ênfase em Estatística, e Doutor em Engenharia de Produção, ênfase em Inteligência Organizacional, ambos também pela UFSC. Atuou como Professor e Coordenador de Curso Superior de Tecnologia, como Coordenador do Núcleo de Tecnologia da Informação e como Coordenador da Faculdade de Tecnologia (CTAI) do SENAI/SC em Florianópolis.Atua como Analista de Inteligência no ObservatóriodaIndústriaCatarinensedaFIESC.Tem experiência nas áreas de Telecomunicações, Ciência daComputação,Estatística,Engenharia de Produção eAdministração,comênfase em Redes Convergentes, Sistemas deInformação,Análise EstatísticadeDados e Geoprocessamento, Inteligência Organizacional, Planejamento Estratégico, Prospectiva Estratégica, Roadmapping e Gestão Educacional.

\section{$* * *$}

